\title{
Integration of GIS and Markov chain model for land use change assessment: A case study in the upstream Ba river basin, Gia Lai province
}

\author{
Hai M. Le ${ }^{1,2}$, Tu H. Le ${ }^{3}$, Dung M. Ho ${ }^{2}$, Nghia T. Nguyen ${ }^{3}$, Ha T. Phan ${ }^{3}$, \\ Phuong N. D. Dang ${ }^{3}$, Loi K. Nguyen ${ }^{3}$, \& Huyen T. Nguyen ${ }^{4 *}$ \\ ${ }^{1}$ Department of Science and Technology, Gia Lai Province, Vietnam \\ ${ }^{2}$ Institute Of Environment and Resources, Vietnam National University, Ho Chi Minh City, Vietnam \\ ${ }^{3}$ Research Center for Climate Change, Nong Lam University Ho Chi Minh City, Vietnam \\ ${ }^{4}$ Faculty of Environment and Natural Resources, Nong Lam University, Ho Chi Minh City, Vietnam
}

ARTICLE INFO
Research Paper
Received: June 24, 2021
Revised: July 23, 2021
Accepted: July 30, 2021
Keywords
Ba river basin
GIS
Land-use change
Markov chain
*Corresponding author
Nguyen Thi Huyen
Email: nt.huyen@hcmuaf.edu.vn

Cited as: Le, H. M., Le, T. H., Ho, D. M., Nguyen, N. T., Phan, H. T., Dang, P. N. D., Nguyen, L. K., \& Nguyen, H. T. (2021). Integration of GIS and Markov chain model for land use change assessment: A case study in the upstream Ba river basin, Gia Lai province. The Journal of Agriculture and Development 20(4), 69-77. 


\title{
Tích hợp GIS và chuỗi Markov trong phân tích động thái thay đổi sử dụng đất: Trường hợp nghiên cửu tại thượng nguồn lưu vực sông $\mathrm{Ba}$, tỉnh Gia Lai
}

\author{
Lê Minh Hải ${ }^{1,2}$, Lê Hoàng Tú ${ }^{3}$, Hồ Minh Dũng ${ }^{2}$, Nguyễn Thành Nghĩa $^{3}$, Phan Thị Hà ${ }^{3}$, \\ Đặng Nguyễn Đông Phương ${ }^{3}$, Nguyễn Kim Lợi ${ }^{3}$ \& Nguyễn Thị Huyền ${ }^{4 *}$ \\ ${ }^{1}$ Sở Khoa Học và Công Nghệ Tỉnh Gia Lai, Gia Lai \\ ${ }^{2}$ Viện Môi Trường và Tài Nguyên, Đại Học Quốc Gia TP.HCM, TP. Hồ Chí Minh \\ ${ }^{3}$ Trung Tâm Nghiên Cứu Biến Đổi Khí Hậu, Trường Đại Học Nông Lâm TP.HCM, TP. Hồ Chí Minh \\ ${ }^{4}$ Khoa Môi Trường và Tài Nguyên, Trường Đại Học Nông Lâm TP.HCM, TP. Hồ Chí Minh
}

\section{THÔNG TIN BÀI BÁO}

Bài báo khoa học

Ngày nhận: 24/06/2021

Ngày chỉnh sửa: 23/07/2021

Ngày chấp nhận: 30/07/2021

Từ khóa

Chuỗi Markov

GIS

Lưu vực sông Ba

Thay đổi sử dụng đất

*Tác giả liên hệ

Nguyễn Thị Huyền

Email: nt.huyen@hcmuaf.edu.vn

\section{TÓM TẮT}

Sông Ba là hệ thống sông lớn nhất của vùng duyên hải Nam Trung Bộ, có vai trò quan trọng trong phát triển kinh tế - xã hội của vùng. Những năm gần đây, thay đổi sử dụng đất trên địa bàn tỉnh Gia Lai có sự chuyển biến mạnh mẽ. Do đó, để có cơ sở cho việc quy hoạch và sử dụng hợp lý nguồn tài nguyên đất, đánh giá thay đổi sử dụng đất ở thượng nguồn lưu vực sông Ba là rất cần thiết. Nghiên cứu sử dụng chuỗi Markov kết hợp với GIS để xem xét sự thay đổi của các loại hình sử dụng đất khác nhau trong giai đoạn 2010 - 2015 và 2015 - 2020. Kết quả cho thấy giai đoạn 2010 - 2015, đất sản xuất nông nghiệp và rừng đặc dụng không có sự thay đổi đáng kể. Trong khi đó, một tỷ lệ lớn đất chưa sử dụng (86\%), nước mặt và nuôi trồng thủy sản $(57,5 \%)$ được chuyển sang các loại hình sử dụng đất khác. Giai đoạn 2020 - 2015, diện tích đất chưa sử dụng tiếp tục giảm trong khi mặt nước và nuôi trồng thủy sản tăng lên. Đất lâm nghiệp chiếm diện tích đáng kể $(51,16 \%)$ trong giai đoạn 2015 - 2020. Ngoài ra, động lực dẫn đến những thay đổi cũng được phân tích, cung cấp cái nhìn toàn diện về thay đổi sử dụng đất tại khu vực nghiên cứu. Nhìn chung, GIS và chuỗi Markov phù hợp cho đánh giá thay đổi sử dụng đất và kết quả của đề tài hữu ích trong việc cung cấp cơ sở cho việc quy hoạch sử dụng đất tỉnh Gia Lai.

\section{1. Đặt Vấn Đề}

Sử dụng đất (SDĐ) là hoạt động của con người tác động vào đất đai theo một mục đích nào đó nhằm đạt kết quả mong muốn (Paul \& Rashid, 2017). Dưới sự tương tác qua lại giữa con người và môi trường, hoạt động $\mathrm{SDĐ}$ có thể bị thay đổi (Briassoulis, 2020). Thay đổi sử dụng đất (TĐSDĐ) là một quá trình phức tạp, làm thay đổi trạng thái của lớp phủ bề mặt, thường được tạo ra bởi các hoạt động của con người trên quy mô không gian và thời gian khác nhau (Pratomoatmojo, 2018). Với sự phát triển kinh tế xã hội và sự gia tăng dân số, mâu thuẫn trong SDĐ đất càng trở nên gay gắt. Vì vậy, ngày càng có nhiều những nghiên cứu về vấn đề TĐSDĐ. Thay đổi sử dụng dất là một trong những đối tượng nghiên cứu chính của biến đổi môi trường toàn cầu và phát triển bền vững (Guan \& ctv., 2011). Các nghiên cứu này góp phần cung cấp cơ sở cho việc hỗ trợ ra quyết định và lập chính sách liên quan (Yang \& ctv., 2014).

Với sự phát triển của GIS, ngày các có nhiều nhà khoa học quan tâm đến những ứng dụng của nó và các công nghệ liên quan như trí tuệ nhân tạo (artificial intelligence), học máy tính (machine-learning) và khai phá dữ liệu (data mining) để mô hình hóa các hệ thống SDĐ (Charif \& ctv., 2017). Các mô hình không chỉ hỗ trợ việc tính toán và dự báo TĐSDĐ trong tương lai mà còn có thể hỗ trợ việc lập kế hoạch SDĐ. Trong đó mô hình Markov, CA (Cellular Automata), ANN (Artificial neural network) và Binary Logistic Regression được sử dụng phổ biến nhằm mô phỏng và dự đoán TĐSDĐ (Islam \& ctv., 2018). Mô hình Markov kết hợp với GIS được cho là một phương 
pháp tiếp cận phù hợp để mô hình hóa sự TĐSDĐ dựa trên ma trận chuyển đổi (Guan \& ctv., 2011; Yang \& ctv., 2014). Phương pháp kết hợp chuỗi Markov và GIS hoặc viễn thám được sử dụng ở nhiều nước trên thế giới như Nhật Bản (Guan \& ctv., 2011), Trung Quốc (Sang \& ctv., 2011), Ấn Độ (Borana \& Yadav, 2017), Brazil (Barros \& ctv., 2018), Parkistan (Tariq \& Shu, 2020), Lào (Faichia \& ctv., 2020) và Việt Nam (Chuong \& ctv., 2017; Hung \& ctv., 2017; Bich \& ctv., 2019).

Lưu vực là một khu vực được xác định bởi các mối liên hệ thủy văn, trong đó quản lý tối ưu đòi hỏi phải có sự đồng bộ của tất cả người sử dụng tài nguyên (Kerr, 2007). Lưu vực thượng nguồn sông $\mathrm{Ba}$, tỉnh Gia Lai có nhiều lợi thế về đất đai, khí hậu và nguồn nước để phát triển kinh tế, đặc biệt là nông nghiệp (Tham \& ctv., 2021). Trong những năm gần đây, TĐSDĐ tỉnh Gia Lai có sự chuyển biến mạnh mẽ. Hiểu rõ TĐSDĐ là bước cơ bản và quan trọng đối với việc quy hoạch và sử dụng nguồn tài nguyên hợp lý. Từ những lý do trên, mục tiêu chung của nghiên cứu là phân tích và đánh giá TĐSDĐ tại lưu vực thượng nguồn sông $\mathrm{Ba}$, thuộc tỉnh Gia Lai, nhằm cung cấp cơ sở hỗ trợ công tác quy hoạch SDĐ trong tương lai. Trong đó, nghiên cứu thực hiện hai mục tiêu cụ thể gồm: (i) xây dựng bản đồ TĐSDĐ tại lưu vực thượng nguồn sông Ba, tỉnh Gia Lai giai đoạn 2010 - 2015 và 2015 - 2020; (ii) Phân tích quá trình TĐSDĐ tại lưu vực thượng nguồn sông $\mathrm{Ba}$, tỉnh Gia Lai ở các giai đoạn trên.

\section{Dữ Liệu và Phương Pháp Nghiên Cứu}

\subsection{Khu vực nghiên cứu}

Lưu vực sông $\mathrm{Ba}$ nằm trong ranh giới hành chính của ba tỉnh Tây Nguyên (Kon Tum, Gia Lai và Đăk Lăk) và một tỉnh thuộc Nam trung bộ (Phú Yên). Lưu vực sông Ba có diện tích tự nhiên khoảng $14.000 \mathrm{~km}^{2}$ (Doan \& ctv., 2019), trong đó tỉnh Gia Lai chiếm khoảng 8.296 km² (Hình 1). Nhìn chung, địa hình phần lưu vực sông Ba thuộc tỉnh Gia Lai rất phức tạp, được tạo ra bởi sự chia cắt của dải Trường Sơn, tạo nên những thung lũng sông có độ dốc lớn với độ cao trung bình 800 - $900 \mathrm{~m}$. Lưu vực sông Ba thuộc tỉnh Gia Lai có khí hậu nhiệt đới gió mùa chịu sự chi phối của địa hình một cách sâu sắc. Do đó, điều kiện tự nhiên lưu vực thượng nguồn sông Ba khá đa dạng, thích hợp cho sự phát triển của nhiều loại hệ sinh thái khác nhau (IPGLPC, 2016).

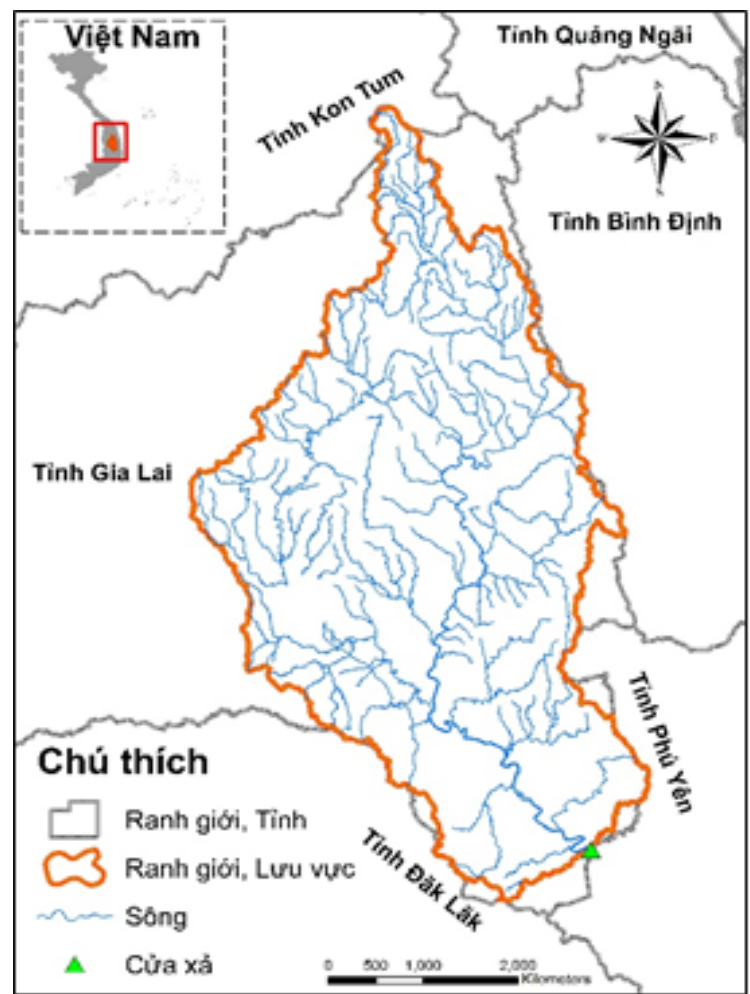

Hình 1. Bản đồ vị trí thượng nguồn lưu vực sông $\mathrm{Ba}$.

\subsection{Dữ liệu và phương pháp}

Dữ liệu hiện trạng SDĐ năm 2010, 2015, và 2020 được cung cấp bởi Sở Tài nguyên và Môi trường tỉnh Gia Lai. Ngoài ra, các thông tin về điều kiện tự nhiên, kinh tế xã hội, báo cáo kiểm kê đất đai hàng năm trong giai đoạn 2010 - 2020 được thu thập từ UBND và Sở Tài nguyên và Môi trường tỉnh Gia Lai nhằm đánh giá và phân tích các nguyên nhân chính tác động đến quá trình TĐSDĐ tại khu vực nghiên cứu.

Nghiên cứu sử dụng chuỗi Markov nhằm xác định sự biến đổi các loại hình SDĐ trong hai giai đoạn 2010 - 2015 và 2015 - 2020. Để thể hiện mối quan hệ giữa SDĐ trong thời điểm ban đầu và các thời điểm tiếp theo, ma trận xác suất chuyển đổi được sử dụng. Ma trận này không chỉ thể hiện sự tăng hay giảm diện tích của các loại hình SDĐ qua các thời điểm khác nhau mà còn cho thấy diện tích của loại hình SDĐ đó đã chuyển đi và/hoặc nhận được từ những loại hình SDĐ khác. Nguyên lý của mô hình Markov được thể hiện tại Hình 2 (Nguyen, 2011). Cụ thể quá trình tính toán cho mô hình Markov có thể được tham khảo từ những nghiên cứu khác (Nguyen, 2011). 
Các kiểu sử dụng đất (SDĐ)

ở thời điểm $\mathrm{t}_{0}$

(1) Kiểu SDĐ 1

(2) Kiểu SDĐ 2

(3) Kiểu SDĐ 3

(4) Kiểu SDĐ 4

(5) Kiểu SDĐ 5

(6) Kiểu SDĐ 6

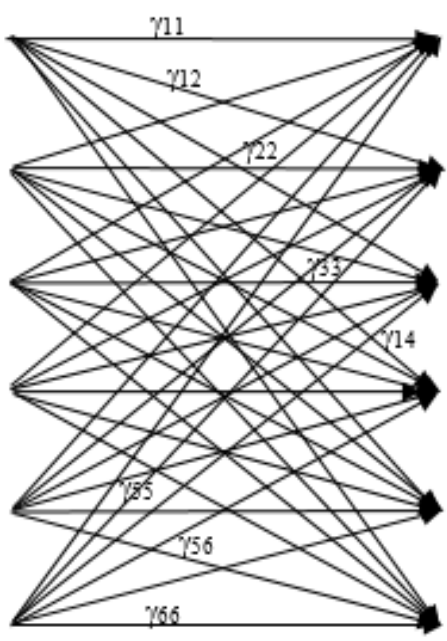

Các kiểu sử dụng đất (SDĐ) ở thời điểm $\mathrm{t}_{1}$

(1) Kiểu SDĐ 1

(2) Kiểu SDĐ 2

(3) Kiểu SDĐ 3

(4) Kiểu SDĐ 4

(5) Kiểu SDĐ 5

(6) Kiểu SDĐ 6

Hình 2. Mô hình chuỗi Markov.

Với $\gamma_{\mathrm{ij}}$ là xác suất thay đổi được xác định từ việc chồng lớp bản đồ $\mathrm{SDĐ}$ tại 2 thời điểm khác nhau. $\gamma_{\mathrm{ij}}$ được xác định bởi công thức: $\gamma_{\mathrm{ij}}$ $=\mathrm{A}_{\mathrm{ij}} / \mathrm{A}_{\mathrm{i}}\left(0 \leq \gamma_{\mathrm{ij}} \leq 1\right)$.

Với $\mathrm{A}_{\mathrm{ij}}$ là diện tích mà loại hình $\mathrm{i}$ chuyển cho loại hình $\mathrm{j}$ ở thời điểm thứ hai, $\mathrm{A}_{\mathrm{i}}$ là diện tích của loại hình $\mathrm{i}$ tại thời điểm thứ nhất.

Cụ thể, tiến trình thực hiện đánh giá TĐSDĐ được thể hiện trong Hình 3. Dữ liệu đầu vào của phương pháp ma trận Markov là bản đồ hiện trạng SDĐ năm 2010, 2015, và 2020. Dữ liệu được chuẩn hóa, gán mã, gộp nhóm và chồng lớp bằng công cụ GIS. Tiếp theo chuỗi Markov được sử dụng nhằm tính toán ma trận biến động theo giai đoạn 2010 - 2015 và 2015 - 2020.

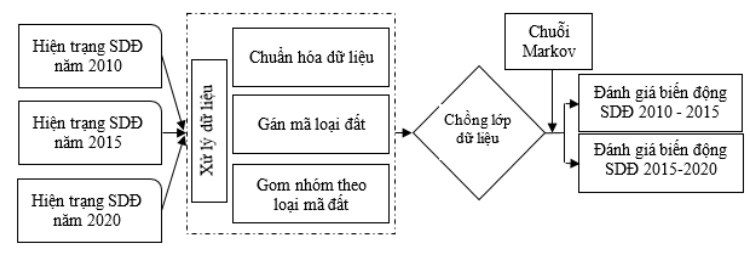

Hình 3. Sơ đồ tiến trình nghiên cứu.

\section{Kết Quả và Thảo Luận}

\subsection{Hiện trạng sử dụng đất}

Dữ liệu hiện trạng SDĐ tại khu vực nghiên cứu bao gồm 40 loại hình được gộp lại thành
08 nhóm chính: đất chưa sử dụng (CSD), đất chuyên dùng (CDG), đất ở (OTC), đất mặt nước và nuôi trồng thủy sản $(\mathrm{SMN})$, dất sản xuất nông nghiệp (SXN), đất rừng đặc dụng (RDD), đất rừng phòng hộ $(\mathrm{RPH})$, và đất rừng sản xuất (RSX). Diện tích và phân bố của từng loại hình SDĐ năm 2010, 2015, và 2020 được thể hiện tại Bảng 1 và Hình 4 .

Năm 2010, nhóm đất rừng có tỷ lệ cao nhất, chiếm hơn $53 \%$ diện tích lưu vực. Nhóm dất sản xuất nông nghiệp chiếm 35\%. Các nhóm SDĐ khác như CDG, CSD, OTC và SMN chiếm 11,44\%. Năm 2015, diện tích đất lâm nghiệp giảm khá mạnh, chiếm 46,41\%. RSX giảm nhiều nhất, khoảng hơn 5\%. SXN tăng mạnh, khoảng 9,75\%. Đến năm 2020, diện tích SXN giảm, chiếm 41,01\% trong khi đất lâm nghiệp tăng, chiếm 51,16\%.

\section{2. Đánh giá thay đổi sử dụng đất}

3.2.1. Thay đổi sử dụng đất giai đoạn 2010 - 2015

Ma trận và phân bố không gian TĐSDĐ giai đoạn 2010 - 2015 được thể hiện tại Bảng 2 và Hình 5. Ma trận cho thây CDG trong giai đoạn 2010 2015 đã chuyển đổi cho các loại hình SDĐ khác khoảng 27\% (4.793,5 ha). Trong đó, $\mathrm{CDG}$ chuyển sang SXN, RSX và OTC với tỷ lệ 16,86\%, 4,96\% và $3,97 \%$. Ngược lại, SMN chuyển đổi thành $\mathrm{CDG}$ với tỷ lệ khá cao (6.559,8 ha chiếm 39,80\%). Nhìn chung, từ 2010 dến 2015, diện tích CDG tăng nhẹ do chuyển dịch cơ cấu kinh tế của tỉnh theo hướng 
Bảng 1. Hiện trạng sử dụng đất (SDĐ) năm 2010, 2015 và 2020

\begin{tabular}{ccccccc}
\hline \multirow{2}{*}{ Nhóm SDĐ } & \multicolumn{2}{c}{ Năm 2010 } & \multicolumn{2}{c}{ Năm 2015 } & \multicolumn{2}{c}{ Năm 2020 } \\
\cline { 2 - 7 } & Diện tích (ha) & $\%$ & Diện tích (ha) & $\%$ & Diện tích (ha) & $\%$ \\
\hline CDG & $17.709,77$ & 2,13 & $22.465,67$ & 2,70 & $17.711,82$ & 2,13 \\
CSD & $31.588,21$ & 3,79 & $11.500,88$ & 1,38 & $1.482,85$ & 0,18 \\
OTC & $29.576,35$ & 3,55 & $30.686,69$ & 3,69 & $29.567,75$ & 3,55 \\
RDD & $23.474,96$ & 2,82 & $24.162,09$ & 2,90 & $25.216,30$ & 3,03 \\
RPH & $85.223,73$ & 10,24 & $67.707,67$ & 8,13 & $87.424,85$ & 10,50 \\
RSX & $337.727,30$ & 40,57 & $294.549,83$ & 35,38 & $313.268,46$ & 37,63 \\
SMN & $16.410,31$ & 1,97 & $9.513,00$ & 1,14 & $16.409,56$ & 1,97 \\
SXN & $290.840,20$ & 34,93 & $371.964,92$ & 44,68 & $341.469,17$ & 41,01 \\
\hline Tồng & $832.550,75$ & 100,00 & $832.550,75$ & 100,00 & $832.550,75$ & 100,00 \\
\hline
\end{tabular}

CDG: đất chuyên dùng, CSD: đất chưa sử dụng, OTC: đất ở, RDD: đất rừng đặc dụng, RPH: đất rừng phòng hộ, RSX: đất rừng sản xuất, $\mathrm{SMN}$ : đất mặt nước và nuôi trồng thủy sản, $\mathrm{SXN}$ : đất sản xuất nông nghiệp.

Bảng 2. Tỉ lệ phần trăm (\%) thay đổi của các loại hình sử dụng đất giai đoạn 2010 -2015

\begin{tabular}{ccccccccc}
\hline & CDG & CSD & OTC & RDD & RPH & RSX & SMN & SXN \\
\hline CDG & 72,93 & 0,29 & 2,11 & 0,03 & 0,31 & 0,20 & 39,97 & 0,46 \\
CSD & 0,14 & 14,00 & 0,03 & 0,29 & 1,39 & 1,55 & 0,06 & 0,18 \\
OTC & 3,96 & 0,33 & 69,46 & 0,01 & 0,07 & 0,09 & 0,78 & 3,04 \\
RDD & 0,05 & 5,15 & 0,00 & 93,78 & 0,09 & 0,07 & 0,04 & 0,07 \\
RPH & 0,59 & 8,11 & 0,18 & 0,54 & 54,04 & 5,30 & 0,46 & 0,29 \\
RSX & 4,97 & 38,88 & 0,62 & 2,43 & 28,29 & 71,31 & 2,33 & 5,26 \\
SMN & 0,51 & 0,16 & 0,40 & 0,01 & 0,05 & 0,22 & 42,50 & 0,52 \\
SXN & 16,85 & 33,08 & 27,19 & 2,92 & 15,76 & 21,26 & 13,87 & 90,18 \\
\hline Tổng 2010 & 100 & 100 & 100 & 100 & 100 & 100 & 100 & 100 \\
\hline
\end{tabular}

CDG: đất chuyên dùng, CSD: đất chưa sử dụng, $\mathrm{OTC}$ : đất ở, RDD: đất rừng đặc dụng, RPH: đất rừng phòng hộ, RSX: đất rừng sản xuất, $\mathrm{SMN}$ : đất mặt nước và nuôi trồng thủy sản, $\mathrm{SXN}$ : đất sản xuất nông nghiệp.
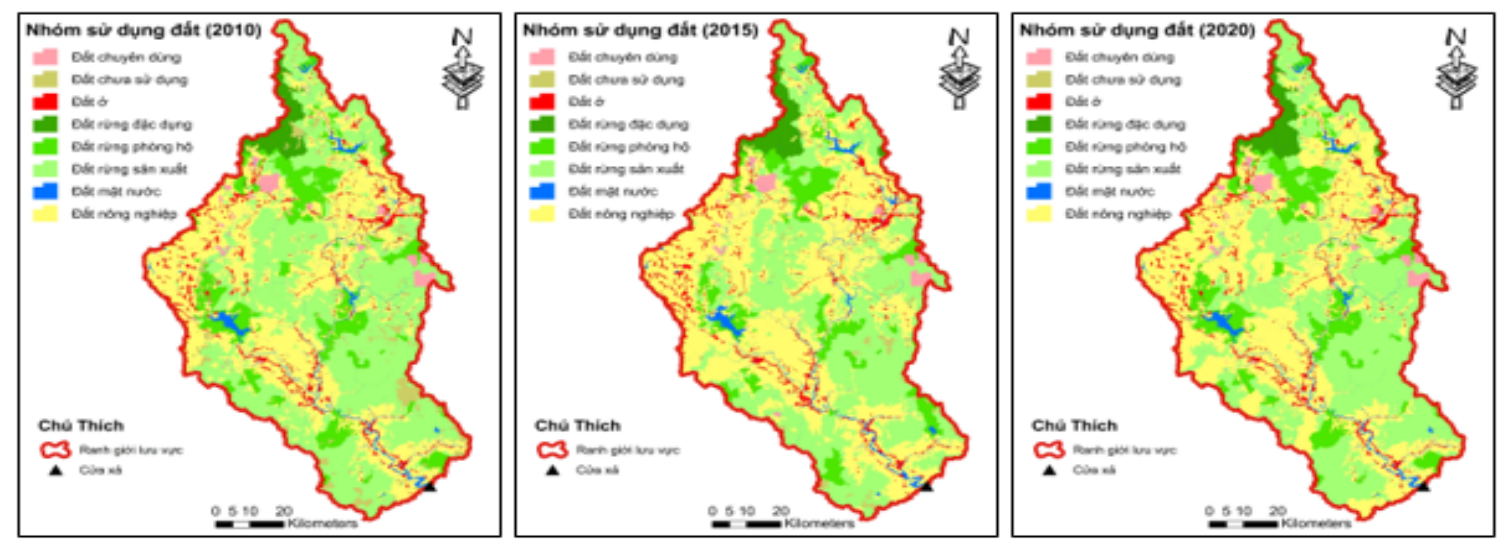

Hình 4. Hiện trạng sử dụng đất năm 2010, 2015 và 2020.

công nghiệp hóa hiện đại hóa nên gia tăng diện tích đất giao thông, văn hóa, giáo dục, y tế, và thể dục thể thao (GLPC, 2016).

Đất chưa sử dụng được giữ lại chỉ chiếm $14 \%$ (4.422,7 ha) diện tích so với năm 2010. Phần lớn CSD được chuyển cho SXN (10.447,9 ha chiếm $33,08 \%$ ) và $\mathrm{RSX}(12.281,1$ ha chiếm $38,88 \%$ ). Đến năm 2015, CSD giảm mạnh gần một phần ba diện tích so với năm 2010. Do nhu cầu sản xuất của người dân tăng lên, nên việc chuyển đổi từ CSD sang các loại đất khác là tất yếu (GLPC, 2016). Đất ở (OTC) tăng nhẹ trong giai đoạn này. Diện tích năm 2010 (29.576,3 ha) tăng lên $(30.686,69$ ha). Điều này phù hợp với xu hướng đô thị hóa 


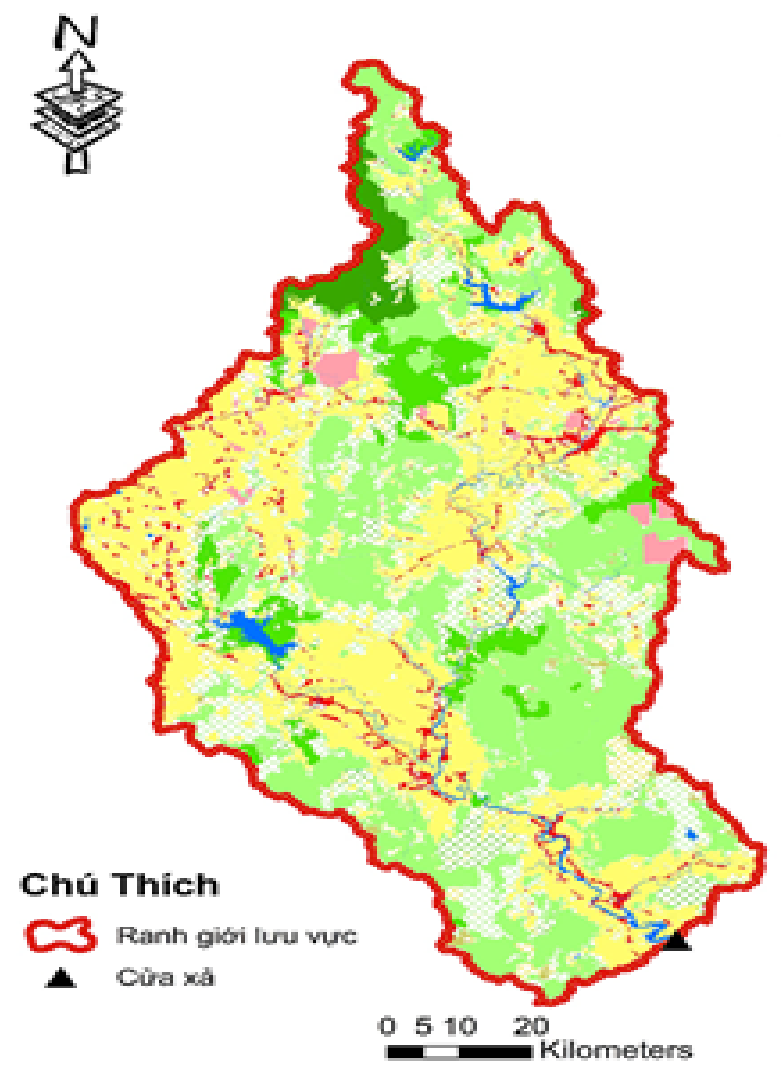

\section{Thay đồi sừ dụng đất (2010-2015)}

Nhơm đất churyển đũng không thay đởi Nhóm đát chuyển dũng thay đởi

Nhơm đất chura sữ đụng khồng thay đồi Nhóm đát chưa sữ đụng thay đơl

Nhớm đất phi nơng nghię̣p khớng thay đời Nhớm đất phi nơng nghięp thay đỏi Nhơm đát rùng đạc dụng khơng thay đobl Nhớm đất rùng đạc dụng thay đới Nhớm đát rùng phòng hộ không thay đới Nhớm đát rù̀ng phòng hộ thay đởi Nhơm đát rừng sàn xuát khồng thay đởi Nhớm đất rùng sản xuất thay đởi Nhơm đát mặt nược khờng thay đỏi Nhơm đát mặ nược thary đởi Nhơm đât nông nghiệp khờng thay đởi Nhơm đất nông nghiẹp thay ob̉i

Hình 5. Bản đồ thay đổi sử dụng đất giai đoạn 2010 - 2015 .

và nhu cầu phát triển kinh tế xã hội. Nhu cầu đất ở của nhân dân tăng lên do tăng dân số tự nhiên và cơ học (GLPC, 2016).

Đối với nhóm đất lâm nghiệp, RDD không biến động nhiều, khoảng 93,78\% (22.013,8 ha) được giữ lại, và $2,92 \%$ chuyển sang $\mathrm{SXN}$. RPH chuyển sang RSX và SXN lần lượt 28,28\% (24.107,6 ha) và $15,76 \%$ (13.432,4 ha). Diện tích đất chuyển từ RPH sang SXN xảy ra tại xã Đê Ar huyện Mang Yang. Việc chuyển đổi đất rừng do Ủy ban nhân dân xã quản lý và giao cho người dân trên địa bàn huyện sản xuất nông nghiệp. Ngoài ra, một phần diện tích rừng được chuyển đổi mục đích sử dụng nhằm phục vụ công trình thủy diện Plei Keo tại các xã Ayun, Bar Maih, Bờ Ngong của huyện Chư Sê. RSX biến động không nhiều, giữ lại khoảng 71,31\% diện tích (240.845,1 ha). Phần còn lại chuyển chủ yếu sang RPH (5,3\%), SXN (21,26\%) (GLPC, 2016).

Đất mặt nước và nuôi trồng thủy sản giữ lại hơn $42 \%$ (6.974,0 ha) phần còn lại được chuyển sang các nhóm khác như CDG và SXN. Giai đoạn 2010 - 2015, SMN giảm diện tích. SXN trong giai đoạn này không có biến động lớn, với hơn $90 \%$ (262.283,2 ha) diện tích không thay đổi. Phần còn lại chủ yếu chuyển sang $\mathrm{OTC}$ và $\mathrm{RSX}$. Điều này phù hợp với việc chuyển đổi cơ cấu cây trồng theo hướng ổn định, có giá trị cao, năng suất cao. Việc chuyển sang trồng cây cây lâu năm như cao su, cà phê, tiêu... mang lại thu nhập cao, ổn định cho nhân dân địa phương (GLPC, 2016).

3.2.2. Thay đổi sử dụng đất giai đoạn 2015 - 2020

Tương tự như giai đoạn 2010 - 2015, TĐSDĐ giai đoạn 2015 - 2020 được tính toán và thể hiện tại Bảng 3 và Hình 6 .

Đất chuyên dùng giảm 42,51\% (4.753,85 ha) và được chuyển qua $\mathrm{SMN}$, OTC và $\mathrm{RSX}$ tương ứng $29,20 \%, 2,78 \%$ và $2,47 \%$. Đất chưa sử dụng chỉ giữ lại 0,45\% diện tích năm 2015. Phần lớn diện tích được chuyển đổi sang RSX (73,29\%), RPH (11,54\%) và SXN (13,36\%). Tổng diện tích CSD giai đoạn 2015 - 2020 tiếp tục giảm mạnh từ $11.500,88$ ha xuống còn $1.482,85$ ha. Do chính sách khuyến khích khai thác để phục vụ cho trồng cây hàng năm, cây lâu năm, trồng rừng là nguyên 
Bảng 3. Bảng tỉ lệ phần trăm sự thay đổi của các loại hình sử dụng đất năm 2015 - 2020

\begin{tabular}{ccccccccc}
\hline & CDG & CSD & OTC & RDD & RPH & RSX & SMN & SXN \\
\hline CDG & 57,49 & 0,22 & 2,35 & 0,04 & 0,16 & 0,30 & 0,96 & 0,80 \\
CSD & 0,08 & 0,45 & 0,04 & 0,00 & 0,21 & 0,09 & 0,11 & 0,27 \\
OTC & 2,78 & 0,09 & 66,92 & 0,01 & 0,08 & 0,06 & 1,25 & 2,16 \\
RDD & 0,03 & 0,98 & 0,01 & 97,84 & 0,19 & 0,20 & 0,03 & 0,20 \\
RPH & 1,42 & 11,54 & 0,19 & 0,33 & 68,43 & 8,33 & 0,76 & 3,96 \\
RSX & 2,47 & 73,29 & 0,80 & 0,89 & 28,64 & 75,53 & 6,68 & 16,48 \\
SMN & 29,20 & 0,08 & 0,42 & 0,02 & 0,11 & 0,13 & 73,30 & 0,61 \\
SXN & 6,53 & 13,36 & 29,28 & 0,87 & 2,18 & 15,36 & 16,91 & 75,53 \\
\hline To̊̀ng 2015 & 100 & 100 & 100 & 100 & 100 & 100 & 100 & 100 \\
\hline
\end{tabular}

CDG: đất chuyên dùng, $\mathrm{CSD}$ : đất chưa sử dụng, $\mathrm{OTC}$ : đất ở, RDD: đất rừng đặc dụng, RPH: đất rừng phòng hộ, RSX: đất rừng sản xuất, SMN: đất mặt nước và nuôi trồng thủy sản, SXN: đất sản xuất nông nghiệp.

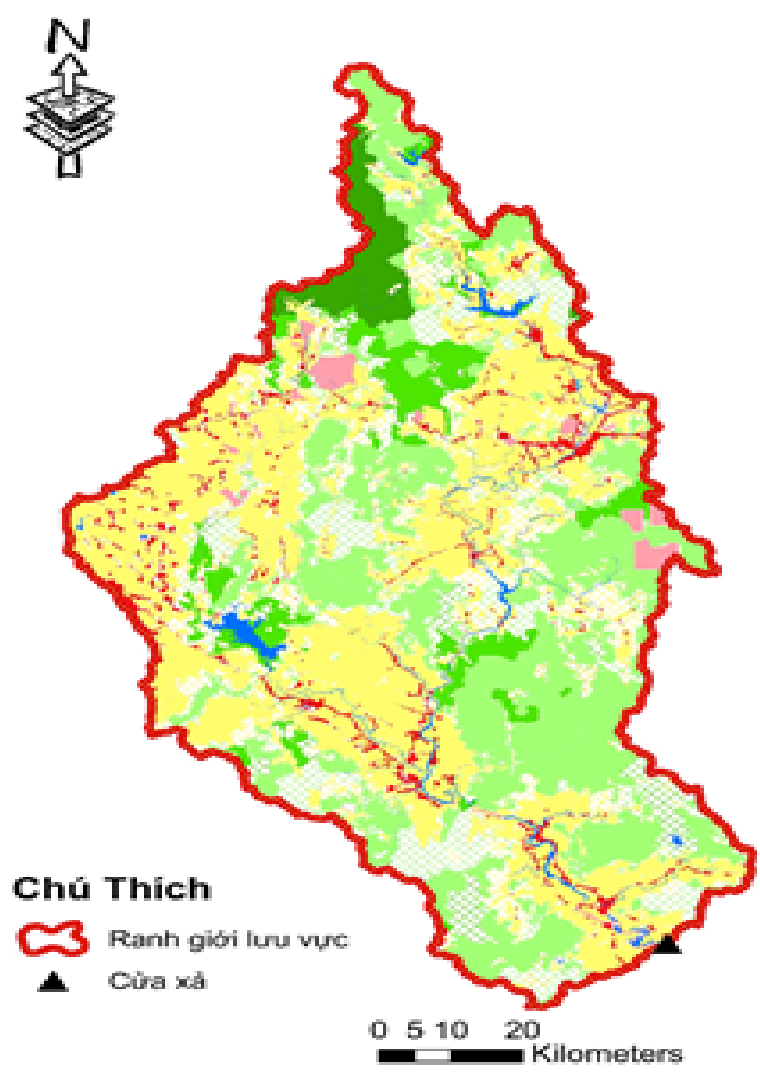

\section{Thay đổi sử dụng đất (2015-2020)}

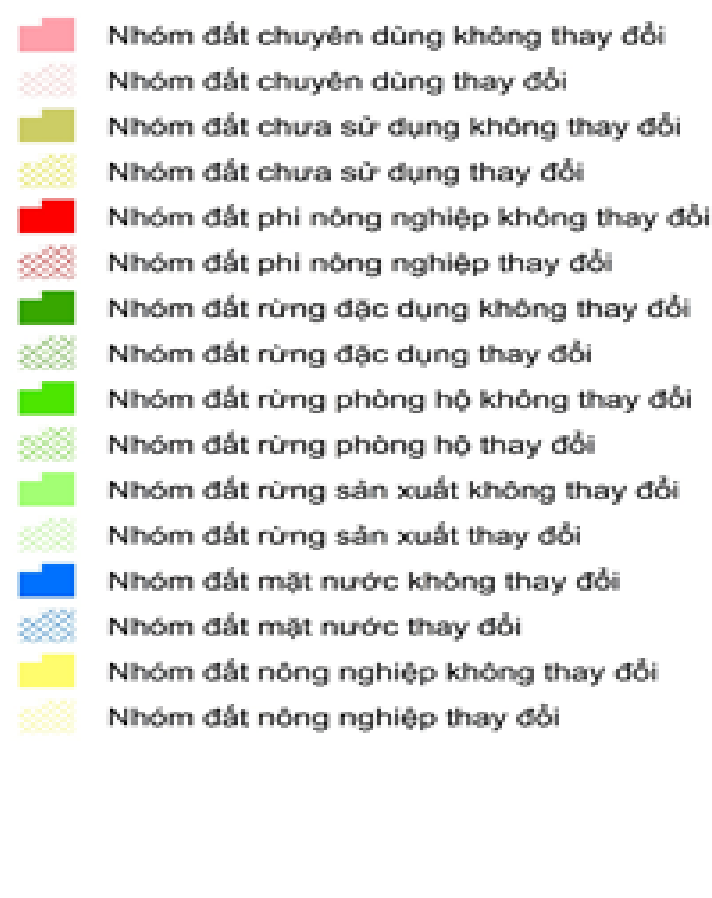

Hình 6. Bản đồ thay đổi sử dụng đất giai đoạn 2015 - 2020 .

nhân dẫn tới sự sụt giảm diện tích CSD (GLPC, 2020). OTC có xu hướng giảm nhẹ từ $30.686,69$ ha năm 2015 xuống 29.567,75 ha năm 2020. Trong đó, một phần diện tích OTC chuyển sang CDG $(2,35 \%)$ và $\mathrm{SXN}(29,28 \%)$. Ở kỳ kiểm kê năm 2014, đất ở được gắn với các đề án quy hoạch nông thôn mới. Vì vậy diện tích đất ở được xác định lớn hơn nhiều so với thực tế sử dụng. Kiểm kê năm 2019, diện tích OTC được tách ra đúng với mục đích sử dụng, do đó diện tích đất ở giảm nhẹ ở giai đoạn này (GLPC, 2020).

Đất rừng đặc dụng được giữ nguyên khoảng $97,84 \%(23.641,27$ ha) và gần $3 \%$ chuyển cho nhóm đất khác. Đất rừng phòng hộ giữ nguyên gần $68,5 \%$ diện tích. Phần còn lại chuyển sang loại hình RSX 28,64\%. Diện tích RPH tăng do được chuyển đổi từ một sổ loại hình SDĐ khác như CSD và RPH. Đất rừng sản xuất có $75,53 \%$ diện tích không thay đổi. Phần diện tích chuyển đổi chủ yếu trở thành $\mathrm{SXN}$ và RPH. Diện tích 
rừng sản xuất giai đoạn này tăng nhẹ do có sự chuyển đổi từ RPH $(28,64 \%)$.

Đất mặt nước và nuôi trồng thủy sản tăng từ 9.513,00 ha lên 16.409,56 ha. Trong đó, có 16, $91 \%$ diện tích SMN chuyển đổi sang SXN, và $29,20 \%$ diện tích CDG chuyển đổi sang SMN. Kỳ kiểm kê năm 2014 khoanh vẽ còn nhiều sai lệch ranh giới giữa đất sông, ngòi, kênh, rạch, suối với các loại đất khác. Kỳ kiểm kê năm 2019, các diện tích đất này được khoanh vẽ và bóc tách cho phù hợp với hiện trạng (GLPC, 2020). Ngoài ra, diện tích SXN giảm nhẹ. Khoảng 16,48\% diện tích chuyển sang RSX. Ngược lại, có khá nhiều các loại hình SDĐ khác chuyển sang SXN như hơn $13 \%$ CSD, hơn $29 \%$ đất ở, hơn $15 \%$ RSX và gần $17 \%$ SMN.

\section{Kết Luận}

Nghiên cứu đã tiến hành xây dựng bản đồ và phân tích TĐSDĐ giai đoạn 2010 - 2020 trên lưu vực thượng nguồn sông sông Ba. Giai đoạn 2010 - 2015, có 04 loại đất tăng diện tích, bao gồm CDG, OTC, RDD và SXN. Những loại hình SDĐ còn lại có diện tích giảm. Trong giai đoạn 2015 - 2020, tương tự, có 04 loại hình SDĐ gia tăng diện tích gồm các loại đất lâm nghiệp như RDD, RPH, RSX, và SMN. Như vậy, CSD giảm dần diện tích, trong khi đó RDD tăng diện tích qua cả hai giai đoạn. Động lực chính dẫn đến sự chuyển đổi qua lại giữa các loại hình SDĐ từ chính sách ưu tiên phát triển kinh tế, xã hội, mở rộng diện tích rừng của tỉnh. Ngoài ra, các công trình thủy điện, thủy lợi cũng góp phần làm biến đổi các loại hình SDĐ. Dân số tăng, nhu cầu xây dựng nhà ở, cơ sở hạ tầng cũng là một động lực quan trọng tác động đến sự chuyển đổi của các loại hình SDĐ. Kết quả nghiên cứu cho thấy, tích hợp GIS và Markov là một phương pháp hiệu quả trong đánh giá TĐSDĐ. Ngoài ra, các động lực dẫn đến những thay đổi này cũng được phân tích, giúp người đọc có cái nhìn toàn diện hơn về TĐSDĐ tại khu vực nghiên cứu. Kết quả cho thấy, các loại hình sử dụng đất biến động chủ yếu do tình hình phát triển kinh tế-xã hội và chính sách phát triển cơ sở hạ tầng của địa phương. Đây là những biến đổi tất yếu phục vụ phát triển kinh tế và nâng cao đời sống người dân. Tuy nhiên, một nguyên nhân quan trọng khác là do sự thiếu nhất quán trong quy trình kiểm kê đất đai. Điều này gây khó khăn cho việc quản lý hiệu quả các loại hình sử dụng đất. Do đó, cơ quan quản lý cần có những chính sách, quy định cư thể, rõ ràng nhằm phân loại các loại hình sử dụng đất hợp lý. Từ đó công tác kiểm kê và phân tích biến động sử dụng đất qua từng thời kỳ được thực hiện dễ dàng và chính xác.

\section{Lời Cam Đoan}

Các thành viên có tên trong bài báo không có bất cứ xung đột lợi ích nào.

\section{Lời Cảm Ơn}

Chúng tôi trân trọng gửi lời cảm ơn đến Sở Khoa học và Công nghệ tỉnh Gia Lai đã hỗ trợ kinh phí thực hiện nghiên cứu này thông qua đề tài: "Xác định tập đoàn giống cây trồng nông nghiệp chủ lực của tỉnh Gia Lai", Mã số: KHGL09-18.

\section{Tài Liệu Tham Khảo (References)}

Barros, K. de O., Alvares Soares Ribeiro, C. A., Marcatti, G. E., Lorenzon, A. S., Martins de Castro, N. L., Domingues, G. F., Romário de Carvalho, J., \& Rosa dos Santos, A. (2018). Markov chains and cellular automata to predict environments subject to desertification. Journal of Environmental Management 225, 160-167.

Bich, N. T., Huyen, N. T., Chien, L. H., Thom, T. T., Oanh, N. T., \& Cuc, B. T. (2019). Application of GIS and remote sensing in agricultural land use change analysis: a case of Luong Son district in Hoa Binh from 2008 to 2018. Science and Technology Journal of Agriculture and Rural Development 18(2), 142-149.

Borana, S. L., \& Yadav, S. K. (2017). Markov chain modelling of land cover changes in Jodhpur City. International Journal of Engineering Development and Research 5(4), 2-7.

Briassoulis, H. (2020). Analysis of land use change: Theoretical and modeling approaches. In Loveridge, S., \& Jackson, R. (Eds.). Lesvos, Greece: WVU Research Repository.

Charif, O., Omrani, H., Abdallah, F., \& Pijanowski, B. (2017). A multi-label Cellular Automata model for land change simulation. Transactions in GIS 21(6), 1298-1320.

Chuong, H. Van, Thong, C. V. T., \& Hung, H. C. (2017). Using Markov chain and GIS to detect and predict land use change in Nha Trang city, Khanh Hoa province. HUAF Journal of Agricultureal Science and Technology 1(1), 37-46.

Doan, T. Q., Tran, D. T., \& Truong, D. D. (2019). Application of meteorological and hydrological drought indices to establish drought classification maps of the Ba River basin in Vietnam. Hydrology 6(2), 49.

Faichia, C., Tong, Z., Zhang, J., Liu, X., Kazuva, E., Ullah, K., \& Al-Shaibah, B. (2020). Using rs data-based 
CA-Markov model for dynamic simulation of historical and future lucc in Vientiane, Laos. Sustainability (Switzerland) 12(20), 8410.

GLPC (Gia Lai People's Committee). (2020). Report on results of land use inventory in 2019. Gia Lai, Vietnam: GLPC Office.

GLPC (Gia Lai People's Committee). (2016). Report on results of land use inventory in 2015. Gia Lai, Vietnam: GLPC Office.

Guan, D. J., Li, H., Inohae, T., Su, W., Nagaie, T., \& Hokao, K. (2011). Modeling urban land use change by the integration of Cellular Automaton and Markov model. Ecological Modelling 222(20-22), 3761-3772.

Hung, T. Le, Nga, N. T. T., Tuyen, V. D., \& Phuong, B. T. (2017). Assessment and prediction of urban land use changes of Hanoi city using remote sensing and GIS techniques. Ho Chi Minh City University of Education Journal of Science 14(3), 176-187.

IPGLPC (Internet Portal Gia Lai People's Committee). (2016). Natural resources. Retrieved April 1, 2020, from https://gialai.gov.vn/gioi-thieu/dieu-kientu-nhien.7.aspx.

Islam, K., Rahman, M. F., \& Jashimuddin, M. (2018). Modeling land use change using cellular automata and artificial neural network: the case of chunati wildlife sanctuary, Bangladesh. Ecological Indicators 88, 439453.

Kerr, J. (2007). Watershed management: Lessons from common property theory. International Journal of the Commons 1(1), 89-110.

Nguyen, L. K. (2011). Sustainable land use and watershed management in response to climate change impacts: overview and proposed research techniques. In Trisurat, Y., Shrestha, R. P., \& Alkemade, R. (Eds.). Land use, climate change and biodiversity modeling: Perspective and applications. Pennsylvania, USA: IGI Global.
Paul, B. K., \& Rashid, H. (2017). Land use change and coastal management. Climatic Hazards in Coastal Bangladesh 2017, 183-207.

Pratomoatmojo, N. A. (2018). LanduseSim Algorithm: Land use change modelling by means of cellular automata and geographic information system. IOP Conference Series: Earth and Environmental Science 202, 012020 .

Sang, L., Zhang, C., Yang, J., Zhu, D., \& Yun, W. (2011). Simulation of land use spatial pattern of towns and villages based on CA-Markov model. Mathematical and Computer Modelling 54(3-4), 938-943.

Tariq, A., \& Shu, H. (2020). CA-Markov chain analysis of seasonal land surface temperature and land use landcover change using optical multi-temporal satellite data of Faisalabad, Pakistan. Remote Sensing 12(20), $1-23$.

Tham, H. T. N., Nguyen, D. T., Pham, T. T. M., Nguyen, H. T. T., \& Lam, N. D. (2021). Assessing the risk of land use change in the centre of the $\mathrm{Ba}$ river basin, Vietnam. IOP Conference Series: Earth and Environmental Science 652, 012017.

Yang, J., Chen, F., Xi, J., Xie, P., \& Li, C. (2014). A multitarget land use change simulation model based on cellular automata and its application. Abstract and Applied Analysis 2014, 375389. 